Dossier: Adorno's Notes on Beckett 


\section{Notes on Beckett}

\section{Translated by Dirk Van Hulle and Shane Weller}

In 1994, the Frankfurter Adorno Blätter (published by the Theodor W. Adorno Archiv) published a dossier, compiled, introduced and annotated by Rolf Tiedemann, documenting Adorno's reading of Beckett's works. Tiedemann notes that Adorno worked on his essay 'Versuch, das Endspiel zu verstehen' from the summer of 1960 to the next spring (Tiedemann, 1994, 26). The text of the essay was mainly written in September 1961. At the end of that month, on 27 February 1961, he presented parts of it at the celebration in Beckett's honour, organised by the German publisher Suhrkamp in Frankfurt am Main.

The next year, in the spring of 1962, Adorno read L'Innommable in a first edition of the German translation by Elmar Tophoven (1959), making notes, both in the margins and on seven pages of the preliminary pages of his copy of Der Namenlose. Rolf Tiedemann also provides some notes Adorno took after a few conversations

\footnotetext{
* Adorno's notes on Beckett were first published in Frankfurter Adorno Blätter III (1994). They appear here in English with the permission of Suhrkamp Verlag, Berlin.

Journal of Beckett Studies 19.2 (2010): 157-178

Edinburgh University Press

DOI: 10.3366/E0309520710000579

www.eupjournals.com/jobs
} 
with Samuel Beckett (between 1958 and 1968) and a letter Adorno sent to Beckett on 4 February 1969.

The present translation focuses on the notes Adorno took to prepare his essay 'Versuch, das Endspiel zu verstehen' (relating the notes to relevant corresponding passages in the essay, translated as 'Trying to Understand Endgame' by Michael T. Jones, New German Critique 26, Spring-Summer 1982, pp. 119-50, and by Shierry Weber Nicholsen in Theodor W. Adorno, Notes to Literature, New York: Columbia University Press, 1991, pp. 241-75) and on his notes for a planned, but never realised essay on L'Innommable. Whenever Adorno had used a particular note while he was writing up his essay on Endgame, he usually struck it through. To indicate this, we have applied Rolf Tiedemann's editorial notation, marking these passages by striking through their source reference. An indication of corresponding passages in Michael T. Jones's translation of the essay follows after the relevant note; page references to the German original in Noten zur Literatur (Adorno, 1981) are followed by the page numbers in Jones's translation (Adorno, 1982). The aim in this translation has been to preserve the telegraphic and sometimes awkward phrasing of the German. On occasion, however, words or phrases have been added for clarification: these appear in square brackets. All underlinings are in the original. The translation follows the chronology of Adorno's notes; the two essays discussing these notes follow the chronology of Beckett's works. We wish to thank Mark Nixon, Ben Hutchinson and Anna Katharina Schaffner for their extremely helpful suggestions on the translation.

\section{Translation of Adorno's Notes on Endgame}

[note 1] One of the possible aspects: literature in the age of the impossibility of humour. What has become of humour. Residual humour. - Humour as regression (clown).

(Noteboek G, p. 83)

[300; trans. 134: 'Psychoanalysis explains clownish humor as a regression back to a primordial ontogenetic level, and Beckett's 
regressive play descends to that level. But the laughter it inspires ought to suffocate the laughter. That is what happened to humor, after it became-as an aesthetic medium-obsolete $\left.(\ldots)^{\prime}\right]$

[note 2] In empirical existence there are innumerable situations which - detached from their pragmatic and psychological contextobjectively assume an expression of their own. An old man takes a nap and pulls a handkerchief over his eyes. Completely harmless in natural life: the horror that emanates from it when isolated in a tableau vivant. B[eckett]'s method consists in releasing such situations and their expression, assembling them in a second, autonomous context. Affinity with the relationship between music and intentions. In a desultory way already in Kafka; in B[eckett] turned into a consistent principle (like serial music vis-à-vis Schönberg). NB Beckett's criticism of Kafka.

(Noteboek G, p. 87ff.)

[297-98; trans. 132: 'then "HAMM: Old stancher! (Pause.) You... remain." Such situations, emancipated from their context and from personal character, are reconstructed in a second autonomous context, just as music joins together the intentions and states of expression immersed in it until its sequence becomes a structure in its own right.']

[note 3] The background. In The Wild Duck, Hjalmar forgets to bring the menu of the dinner at the old Werle's to his daughter, as promised. This is psychologically motivated and at the same time symbolic in the strict sense of Freudian parapraxis. When this symbolism is disconnected from its psychological determination, it simultaneously acquires an objective, concrete aspect; it becomes the carrier of the dramatic idea, as in the later works (e.g. the clerk [Vilhelm Foldal] being run over in John Gabriel Borkman). If, from these objective symbols, one extracts those meanings, the relationship with the-problematic-idea, one is left with code signs of an $x$. That is the genesis of the absurd. - Beckett relates to Kafka the way the serial composers relate to Schönberg. His 
criticism of Kafka contains the same problem as the integral composition in its relationship to the antagonistic one.

(Noteboek G, p.93)

[304; trans. 137: 'What becomes of form in Endgame can be virtually reconstructed from literary history. In Ibsen's The Wild Duck, the degenerate photographer Hjalmar Ekdalhimself a potential anti-hero (...) the accountant Foldal is overcome by so-called "youth."']

[305; trans. 137: 'Drama need only become aware of the ineluctably ridiculous nature of such pan-symbolism, which destroys itself; it need only take that up and utilise it, and Beckettian absurdity is already achieved as a result of the immanent dialectic of form. Not meaning anything becomes the only meaning.']

[303; trans. 136: 'Beckett's drama is heir to Kafka's novels, to whom he stands in a similar relation as the serial composers to Schönberg.']

[note 4] The great closing scene in Fin de partie is the parody of the scène à faire, become impossible.

(Notebook G, p. 97)

[note 5] The origin of the notion of the situation in Jaspers has to be noted, and at the same time the difference from it-from his subjectivism - needs to be sharply determined. In this regard, compare Rickert's passage on the physiognomy of the objective mind.

(Notebook G, p. 100.1)

[294; trans. 129: 'It [the "situation"] is defined by Jaspers as "a reality for an existing subject who has a stake in it" (...) he also calls it "not just a reality governed by natural laws. It is a senserelated reality," a reality moreover which, strangely enough, is said by Jaspers to be "neither psychological nor physical, but both in one." When situation becomes-in Beckett's view - actually both, it loses its existential-ontological constituents: personal identity and meaning.']

[295; trans. 130: 'These Beckettian situations which constitute his drama are the negative of meaningful reality. (...) Beckett's treatment of these situations, that panicky 
and yet artificial derivation of simplistic slapstick comedy of yesteryear, articulates a content noted already in Proust. In his posthumous work Immediacy and Sense-Interpretation, Heinrich Rickert considers the possibility of an objective physiognomy of mind $\left.(\ldots)^{\prime}\right]$

[note 6] The enigmatic and the physiognomy of the objective mind. The situations say something - but what? NB very similar to music.

(Noteboek G, p. 100.2)

[296; trans. 130-31: 'The physiognomy of objective expression however retains an enigma. The situations say something, but what?' (...) Proust, in a subterranean mystical tradition, still clings affirmatively to that physiognomy, as if involuntary memory disclosed a secret language of things; in Beckett, it becomes the physiognomy of what is no longer human. (...) [132] Such situations, emancipated from their context and from personal character, are reconstructed in a second autonomous context, just as music joins together the intentions and states of expression $\left.(\ldots)^{\prime}\right]$

[note 7] The simplest not to be withheld: the experience of existence as absurd. Yet this experience is not ontological but historical.* [*(note by Adorno) Absurdity has its historical side: for people do not themselves determine their lives in a transparent way.] The basis of this experience is the loss of faith in providence and a meaningful encapsulation of life; the explosion of cosmology; the dilapidation and problematisation of order-producing structures to which that meaning used to be attached; the immediate threat to the survival of the species. As soon as reason, released and terminal, needs to look for a meaning, it has no other answer than this nothingness: it is the apriori of the question. In this context, it is crucial that such historical answers always necessarily appear to be ontological, without history; that is precisely the blinding element, the bewitchment. B[eckett]'s genius is that he has captured this semblance of the non-historical, of the condition humaine, in historical images, and thus transfixed it. The ideology of the condition humaine is replaced by dialectical images.

(Notebook G, p. 100ff.) 
[287; trans. 123: 'What would be called the condition humaine in existentialist jargon is the image of the last human, which is devouring the earlier ones-humanity. Existential ontology asserts the universally valid in a process of abstraction which is not conscious of itself. While it still-according to the old phenomenological doctrine of the intuition of essence-behaves as if it were aware, even in the particular, of its binding determinations, thereby unifying apriority and concreteness, it nonetheless distills out what appears to transcend temporality.']

[319; trans. 148: 'The historical inevitability of this absurdity allows it to seem ontological; that is the veil of delusion produced by history itself. Beckett's drama rips through this veil. The immanent contradiction of the absurd, reason terminating in senselessness, emphatically reveals the possibility of a truth which can no longer even be thought; it undermines the absolute claim exercised by what merely is. Negative ontology is the negation of ontology: history alone has brought to maturity what was appropriated by the mythic power of timelessness.']

[note 8] There is something absurd in the form of the dialogue itself; meaninglessness of the question-and-answer relationship; gibberish (connection with Ionesco); chatter as trivial reflex of the objective world, second language. Hearing oneself talking is like watching a Beckett play. Analyse this moment accurately. One is alienated from one's own language by $\mathrm{B}\left[\right.$ eckett]. ${ }^{*}$ (note by Adorno) Situation: One cannot talk any longer. Text p. 22.]

(Noteboek G, p. 102)

[305; trans. 138: 'Rather than striving to liquidate the discursive element of language through pure sound, Beckett turns that element into an instrument of its own absurdity and he does that according to the ritual of clowns, whose babbling becomes nonsensical by presenting itself as sense. The objective disintegration of language - that simultaneously stereotyped and faulty chatter of self-alienation, where word and sentence melt together in human mouths-penetrates the aesthetic arcanum. The second language of those falling silent, a conglomeration of insolent phrases, pseudo-logical 
connections, and galvanised words appearing as commodity signs - as the desolate echo of the advertising world-is "refunctioned" (umfunktioniert) into the language of a poetic work that negates language. Beckett thus approximates the drama of Eugène Ionesco.']

[note 9] The play is the only attempt in grand style to hold out against the potential of total destruction-like Picasso's Guernica, Schönberg's Survivor [from Warsaw, Op. 46, 1947] against the horrors of the Hitler era. With utmost decisiveness B[eckett] has stuck to the narrow ridge of what is still possible. On the one hand he has realised that absolute destruction-to which no individual human being's experience extends-cannot become thematic directly. The word atom does not appear (although it does in the corollary All That Fall). There are no atomic conflicts à la Blaues Licht. Everything is shown only through the reflection of the experience, as it were in a subcutaneous expressionistic inwardness (reminiscent of Strindberg's Dödsdansen [The Dance of Death]). Absolute limit of technological utopia, of science fiction. But at the same time the possibility of experience, and the number of subjects, is so reduced that it can only be conceived as a consequence of the catastrophe. In a way the latter endorses the process of historical regression. - On the other hand nothing evaporates into the purely symbolical. The situations are real, and they are pragmatic presuppositions (partial end of the world), developed with utmost discretion. Parody of the exposition in traditional drama, in which the background information is presented, dispersed (end of organic life, the sunken lighthouse. The protagonists' blindness and paralysis as consequence of the catastrophe?[)]-It is as if consciousness wished to endure the end of its own physical presence, while looking it in the face. Connection with Proust.

(Noteboek G, p. 103ff.)

[321; trans. 150: 'Consciousness begins to look its own demise in the eye, as if it wanted to survive the demise, as these two want to survive the destruction of their world. Proust, about whom the young Beckett wrote an essay, is said to have attempted to keep protocol on his own struggle with death, 
in notes which were to be integrated into the description of Bergotte's death. Endgame carries out this intention like a mandate from a testament.']

[note 10] In my work on Kafka, I have reproached Gide for his stage adaptation [of Kafka's The Trial], arguing that drama is not possible without subject and freedom. That is where Fin de partie sets in. The question is: what is possible in terms of drama without subject and without the possibility of freedom. It is precisely in this way that the play becomes a parody of drama and all its categories.

(Notebook G, p. 105)

[302; trans. 136: 'Dramatic categories as a whole are treated just like humor. All are parodied. But not ridiculed. (... ')]

[note 11] Parody of drama $=$ drama in the age of its impossibility. In tragedy, stychomythia served as a tool to tighten the dramatic tension to the utmost: quintessence of antithesis. Here it turns into slackening: less and less talkative protagonists, complete regression (as in positivism: talking in short sentences).

(Notebook G, p. 106.1)

[303; trans. 136-37: 'For example, tragedy, at the height of its plot and with antithesis as its quintessence [trans. Weber: 'as the quintessence of antithesis'; Adorno, 1991, 260], manifested the utmost tightening of the dramatic thread, stichomythia-dialogues in which the trimester spoken by one person follows that of the other. (...) Beckett employs it as if the detonation had revealed what was buried in drama. Endgame contains rapid, monosyllabic dialogues, like the earlier question-and-answer games between the blinded king and fate's messenger. But where the bind tightened then, the speakers now grow slack. Short of breath until they almost fall silent, they no longer manage the synthesis of linguistic phrases; they stammer in protocol sentences that might stem from positivists or Expressionists.']

[note 12] The Endgame is a draw, isn't it?

(Notebook G, p. 106.2) 
[note 13] Tremendous richness of allusions and links: the malignant joke, she cries ergo she lives etc., as in [Herman] Bang.

(Notebook G, p. 107)

[note 14] The relation to history is expressed by means of a taboo. The shock is such that it cannot be talked about. It is even noticeable in the way the play is composed. The catastrophe, which is clearly the pragmatic presupposition, cannot be named. Corresponds more or less to the way people in Germany in 1960 talk about the murder of the Jews in attenuating allusions.

(Notebook G, p. 109ff.)

[287; trans. 123: 'The violence of the unspeakable is mimicked by the timidity to mention it. Beckett keeps it nebulous. One can only speak euphemistically about what is incommensurate with all experience, just as one speaks in Germany of the murder of the Jews.']

[note 15] What about the game of chess?

1) the empty field, remainder, the destruction only allegorically readable in the result.

2) endgames are regulated, prescribed by a system; they can only change by means of errors, not by means of preferences.

3) as in chess, winners and losers are dependent on each other.

4) chess as a situation (separated from human beings, and yet they are present through the agency of the king. The king is the remainder of the subject). The meaninglessness, the folly in the game's seriousness.

5 ) in the endgame, the best that can happen to the losing party is a draw. Situations such as stalemate, perpetual check. Bad infinity.

(Noteboek G, p. 110ff.)

[288; trans. 125: 'Drama falls silent and becomes gesture, frozen amid the dialogues. Only the result of history appears - as decline.'] 
[316; trans. 146: 'The field is almost empty, and what happened before can only be poorly construed from the positions of the few remaining figures.']

[316; trans. 146: 'Only artistic mistakes or accidents, such as something growing somewhere, could cause unforeseen events $\left.(\ldots)^{\prime}\right]$

[316; trans. 146: 'Hamm is the king, about whom everything turns and who can do nothing himself. The incongruity between chess as pastime and the excessive effort involved (... '] [316; trans. 146: 'Whether the game ends with stalemate or with perpetual check, or whether Clov wins, remains unclear, as if clarity in that would already be too much meaning.']

[293; trans. 128: 'While meanings in Kafka were beheaded or confused, Beckett calls a halt to the bad infinity of intentions: their sense is senselessness.']

[note 16] Beckett[:] something about existentialism's change of function and its cause needs to be included in the text

(Notebook G, p. 111)

[note 16a] 'simple fare' [Hausmannskost]: The totalitarians' ranting against decadence has its reason. It has to do with utopia. What a quantity of satiation, tedium, dégoût is needed to want something that would be completely different. The newcomer is impressed by everything that is, to such an extent that he never rises against it. Health means: to make do with the nourishment offered. (see Tiedemann, 1994, 75 note 28)

[283-84; trans. 121: 'Totalitarians like Lukács, who rage against the - truly terrifying - simplifier as "decadent," are not ill advised by the interests of their bosses. They hate in Beckett what they have betrayed. Only the nausea of satiation - the tedium of spirit with itself-wants something completely different: prescribed "health" nevertheless makes do with the nourishment offered, with simple fare. Beckett's dégoût cannot be forced to fall in line.']

[note 17] A primitive historical intention would be just as senseless as the ontological intention attributed to B[eckett] by Lukács. 
No struggle against atomic death. Neither condition humaine nor Ape and Essence. A third option: the horror of the whole flares up in-only in-that of the last element (proofs). The human being as what he became. The fate of the species is decided upon on its last day - as in utopia.

B[eckett]'s refusal to explain (difference from Sartre and Camus) corresponds with the unsolvability. But as little of a realist or realistsymbolist as Kafka. Whereas in Kafka meaning is broken off or confused, one could perhaps say that in $\mathrm{B}$ [eckett] the meaning is the meaninglessness (parody of philosophy, which transfigures thrownness into meaning). But it is not a universal-which would turn it into an idea again-but the expression of more specific situations than its horror.

(Notebook G, p. 112ff.)

[293; trans. 128: 'While meanings in Kafka were beheaded or confused, Beckett calls a halt to the bad infinity of intentions: their sense is senselessness. Objectively and without any polemical intent, that is his answer to existential philosophy, which under the name of "thrownness" and later of "absurdity" transforms senselessness itself into sense, exploiting the equivocations inherent in the concept of sense. To this Beckett juxtaposes no world view, rather he takes it at its word. What becomes of the absurd, after the characters of the meaning of existence have been torn down, is no longer a universal-the absurd would then be yet again an idea-but only pathetic details which ridicule conceptuality $\left.(\ldots)^{\prime}\right]$

[note 18] Heidegger's states of being [Befindlichkeiten], Jaspers' situations have become materialistic in B[eckett]. The threshold against existentialism is the denial of inwardness.

(Notebook G, p. 114.1)

[293; trans. 129: 'Removed from their inwardness, Heidegger's states of being (Befindlichkeiten) and Jaspers' "situations" have become materialistic (...) As soon as the subject is no longer doubtlessly self-identical, no longer a closed structure of meaning, the line of demarcation with the exterior becomes 
blurred, and the situations of inwardness become at the same time physical ones.']

[note 19] The humour of the last human being: that is the humour that can no longer count on any laughing. B[eckett] has recovered for humour what otherwise only applies to the categories of the Arts with a capital A-which he tacitly liquidates: the resignation of communication.

(Notebook G, p. 114.2)

[301; trans. 134: 'Beckett carries out the verdict on humor. The jokes of the damaged people are themselves damaged. They no longer reach anybody $\left.(. . .)^{\prime}\right]$

[307; trans. 139: 'Communication, the universal law of clichés, proclaims that there is no more communication. The absurdity of all speaking is not unrelated to realism but rather develops from it. For communicative language postulates-already in its syntactic form, through logic, the nature of conclusions, and stable concepts - the principle of sufficient reason. Yet this requirement is hardly met anymore $\left.(. . .)^{\prime}\right]$

[note 20] The play takes place in a no man's land, a zone of indifference between inner and outer. What remains of these two in a state of complete alienation. Concentration camp, intermediate domain between life and death, life as a knacker's yard.

(Notebook G, p. 114ff.)

[292; trans. 127-28: 'Endgame takes place in a zone of indifference between inner and outer, neutral between - on the one hand - the "materials" without which subjectivity could not manifest itself or even exist, and - on the other-an animating impulse which blurs the materials, as if that impulse had breathed on the glass through which they are viewed.']

[293; trans. 128: 'Endgame occupies the nadir of what philosophy's construction of the subject-object confiscated at its zenith: pure identity becomes the identity of annihilation, identity of subject and object in the state of complete alienation.'] 
[note 21] Essence and existentialism. Break from rationalism. Focus on the essential. Expression of increasing irrationality. Through polemic against rationalism and positivism not apologetic. Lacking the theological, both open and hidden.-Residues of global annihilation.

(Notebook G, p. 115.1)

[note 22] Existence in Beckett: minimum of existence.

(Notebook G, p. 115.2)

[284; trans. 121: 'Existentialism itself is parodied; nothing remains of its "invariants" other than minimal existence.']

[note 23] Compare with chapter 6 in my Kafka, beware of overlap. (Notebook G, p. 115.3)

[Theodor W. Adorno (1998), 'Aufzeichnungen zu Kafka', in Gesammelte Schriften 10.1 (Kulturkritik und Gesellschaft I), Darmstadt: Wissenschaftliche Buchgesellschaft, pp. 271-73.]

[note 24] Parody of both philosophy and drama (the two converge: revolt against the content).

(Notebook G, p. 115.4)

[284; trans. 121: 'He responds to the cheery call to play along with parody, parody of the philosophy spit out by his dialogues as well as parody of forms.']

[note 25] The end of the world is already discounted.

(Notebook G, p. 115.5)

[286; trans. 123: 'The end of the world is discounted, as if it were a matter of course. Every supposed drama of the atomic age would mock itself, if only because its fable would hopelessly falsify the horror of historical anonymity by shoving it into the characters and actions of humans $\left.(\ldots)^{\prime}\right]$

[note 26] No individual can lodge complaint any longer (Wolfskehl). He [Beckett] does not indict society. Certainly not, and that is precisely the spearhead which he aims at it. Against Lukács 
and vulgar Marxist interpretation. - Presupposition that all of that is smothered. In time. In addition the missed moment.

(Notebook G, p. 116)

[290, trans. 126: 'The vanity of the individual who indicts society, while his rights themselves merge in the accumulation of the injustice of all individuals - disaster itself-is manifest in embarrassing declamations like the "Germany" poem of Karl Wolfskehl. The "too-late," the missed moment condemns such bombastic rhetoric to phraseology. Nothing of that sort in Beckett.']

[note 27] The hieratic language alone turns the radicalism of existential ontology into a lie. While one confronts nothingness, while everything is being questioned, the bathos of this questioning already warrants the meaning it pretends to know nothing about. The implicit 'nevertheless'. Cryptotheology.

(Notebook G, p. 117ff.)

[note 28] Take the theological 'unto dust shalt thou return' literally: filth [Dreck], the most intimate, chamber pot, piss, pills are the universal as remainder. Abstractionism and concretism.

(Notebook G, p. 119.1)

[321; trans. 150: 'To be sure, the Old Testament saying "You shall become dust (Staub) again" is translated here into "dirt" (Dreck). In the play, the substance of life, a life that is death, is the excretions.']

[287; trans. 123-24: 'Existential ontology asserts the universally valid in a process of abstraction which is not conscious of itself. (...) It does so by blotting out particularity - what is individualized in space and time, what makes existence existence rather than its mere concept. Ontology appeals to those who are weary of philosophical formalism but who yet cling to what is only accessible formally. To such unacknowledged abstraction, Beckett affixes the caustic antithesis by means of acknowledged subtraction. (...) He lengthens the escape route of the subject's liquidation to the point where it constricts into a "this-here," whose abstractness - the loss 
of all qualities-extends ontological abstraction literally ad absurdum $\left.(\ldots)^{\prime}\right]$

[note 29] Homini sapienti sat. Take decadence positively, see p. 112 of this notebook. B[eckett] relates to culture as to a single swarm of Jugendstil ornaments.

(Notebook G, p. 119.2)

[284; trans. 121: 'Thoughts are dragged along and distorted like the day's left-overs, homo homini sapienti sat.']

[281; trans. 119: 'Culture parades before him as the entrails of Jugendstil ornaments did before that progress which preceded him, modernism as the obsolescence of the modern. The regressive language demolishes it.']

[note 30] The last image is a tableau vivant of a clown, corresponding exactly to the opening scene: with the exception of Clov's possibly decisive travel outfit. Thus it remains open whether it starts all over again or is finished. Berg (Wozzeck!)

(Notebook G, p. 120)

[314; trans. 145: 'He does manage to make the decision to go, even comes in for the farewell (...) a strong, almost musical conclusion. (...) Aside from some differences, which may be decisive or completely irrelevant, this is identical with the beginning.']

[316; trans. 146: '(...) whether Clov wins, remains unclear, as if clarity in that would already be too much meaning.']

[note 31] Addition re language. B[eckett]'s progressiveness accords with an idiosyncratic touchiness against modernism. Removal of ornaments. In B[eckett], the objectivity is so hidden that-by removing the meaning-it becomes mysterious and starts to fluoresce.

(Noteboek G, p. 128ff.)

[281; trans. 119: '(...) modernism as the obsolescence of the modern. The regressive language demolishes it. Such objectivity in Beckett obliterates the meaning that was culture, along with its rudiments. Culture thus begins to fluoresce.'] 


\section{Translation of Adorno's Notes on The Unnamable}

1

The ' $\mathrm{I}$ ' of the beginning and the one at the beginning of the Recherche

Prolegomena to B[eckett]

Against the 'it can't go on'

Necessity to read each sentence rigorously from beginning to end

The poem with the outbursts of hatred [i.e. Whoroscope]

[In left-hand margin:] see e.g. p. 103 [p. 338 in Calder edition of the three novels]

On the situation: absolute alienation is

the absolute subject. But precisely that subject is alienated

from itself, it is the other, it is nothing.

B[eckett]'s novels are the critique of solipsism.

Nothing leads out of this dialectic in his work

At the same time it is the movens: the anything goes

there is an inherently univocal B[eckett] world, like

Kafka's

[In left-hand margin:] Mahood

$\mathrm{B}$ [eckett] reaches the point of indifference between narrative and theory, just as Marx (and Hegel) wanted

to transform philosophy into history

Completion of the tendency towards the reflexive novel

[The word 'novel' is written in the right-hand margin]

Not despairing: schizoid apathy. Not even

able to suffer any more.

The fact that B[eckett] retains the label 'novel'. What has become of the novel.

something infinitely liberating comes from B[eckett] vis-à-vis death. What is it?

[The next entry is marked with a vertical line in the left-hand margin] 
Possibility of interpreting B[eckett] as an attempt

to [respond to] the biblical 'unto dust shalt thou return'. Asking, as in the

catechism: What does that mean, 'I am dust'.

Is it consoling that this question is answered?

\section{2}

B[eckett]'s deep affinity with music. Like his monologue,

music too always says ' $\mathrm{I}$ ', but its ' $\mathrm{I}$ ' too is

always an other, identical and non-identical

at the same time.

The pantheist says: after death I shall be flower, leaf, earth.

$\mathrm{B}$ [eckett] puts this to the test: what am I if I am filth [Dreck].

$\mathrm{B}$ [eckett] as parody of the philosophy of the remainder

(full of al-

lusions to Descartes). The p[hilosophy of the remainder] says:

what

remains for me

after the deduction of all costs, surcharges, trimmings, ad-

vertising as absolute certainty - consciousness as

property, the secret of mineness [Jemeinigkeit], which not for no-

thing sounds like meanness [Gemeinheit]. In B[eckett] that becomes,

sardonically: how can I ligate everything that exists

and also

myself? (This is thought in accordance with the capital-

ist market, which B[eckett] takes at its word.)

Answer: by turning myself into a negative

quantity, into less than nothing (filth and

stump are less than a remnant). The sovereign

ego cogitans is transformed by the dubitatio into

its opposite. And that is what it always was.

For in order to retain itself as absolutely certain

it had to turn itself into ever less. Sov-

ereignty and filth belong together already in

Kafka; in B[eckett] they become one. The Western

process of subjective reduction calls itself by its

proper name. 
There are traces in $\mathrm{B}[$ eckett] of an antinomian but Marcionist theology, like that of God as a sports fan (in him the Epicurean gods come into their own). But that too is not to be taken $\grave{a}$ la lettre, rather as a grimace.

No?

3

$\mathrm{B}$ [eckett] has a panic-stricken fear of tape-recordings and suchlike. And yet he wrote La Dernière

Bande. A hole into the work? All that written as an adjuration: in order not to have to resemble in any way what is presented? B[eckett] - the composition of his works proves this - has a very strong 'I'.

The thought of the defensive adjuration and that of ligation belong immediately together.

From Kafka the most effective motif [is] that of the Hunter Gracchus. Death, silence, without voices, as the unattainable goal. Living is dying because it is a not-being-able-to-die.

The clownish reflections on the work itself are reminiscent of Gide's Paludes, in fact much is - it is, besides Kafka, the most important link.

The fellow beings - 'they', the voices - appear as the absolute negative because they prevent dying.

The famous metaphysical question: why is there something and not simply nothing, turns, in accordance with the form, into something like a Jewish joke: You're right, why on earth is there something and not simply nothing! ('You're right, Lieutenant, why should the soldier not cross the parade ground with a lit cigarette in his mouth.') 
Criticism of B[eckett] amounts to the statement: but all that is terrible, it simply cannot be. Answer:

it is terrible.

The question of whether the absolutely qualityless point of indifference, which in $\mathrm{B}$ [eckett] is the negative, could not just as well be the positive. But no, the qualityless, the indeterminate - the abstract is precisely the negativity.

4

perhaps include the note on nihilism from notebook $\mathrm{M}$

In the light of each new work by B[eckett]

the earlier ones appear simple.

[In left-hand margin:] Difference from Joyce

In $\mathrm{B}$ [eckett] there is, as a kind of

counterpoint, something like sound

common sense. Everything

so meaningless, yet at the same time the way one speaks

is so normal, i.e. modern language may have

shrunken-compared with Kafka's epic language, brought as it were to

the point of indifference with the absolute subject -

but [it is] never replaced by linguistic absurdity. In that respect

similar to Brecht. Beckett, a Dadaist without Dada.

How my formula of the solipsist without ipse

comes into its own in him.

L'innom $[m]$ able is the negative subject-object

'Vergammeln' [To go to seed]. It would be important to know when this

word first appeared; index of B[eckett]'s historical significance.

What Beckett does is to compose out this word.

Lukács has observed the emancipation

of time empty of meaning in L'Éducation sentimentale. The history of the novel thereafter is that of the ever more naked emergence of time. With the monologue intérieur it emancipates itself from that which is, from the existent. 
As a result, however, time itself disintegrates, already in Proust, completely in $L^{\prime}$ Innom [m]able. Absolute time ceases to be time-just as the Kantian conception of time as pure form cannot be maintained, because it cannot be represented without the something of which it is the time [ein Woran] (transition to the dialectic).

pure temps durée turns into

temps espace. That is precisely what occurs in L'I[nnommable].

The spatial interior is merely space, proofs of that.

Almost all new art has to pay bitterly for the fact that it cannot hold out at this point [auf dem Punkt]. It cannot (quote a form). Beckett is the only one who

5

absolutely consistently refuses to go beyond this point. That is the problem; any jackass hears the repetition. But that is also precisely his aesthetic task: all that is still possible at one point.

At the end of the work perhaps: The man who said one doesn't know whether [one is] living or dead. The negative truth therein (Kaiser). But

also the contrary, a metaphysics, experience of a condition beyond death and life (Kafka!). - No spirits. Indicated in dreams. What is that.

Perhaps include in the work the notes taken in Bregenz on nihilism; also a note in an earlier notebook

Simplest answer to why [L'Innommable is] so enormously significant:

because it comes closest to the conception of what it will really be like after death (the innommable dreams it). Neither spirit nor time nor symbol. This is precisely the Beckettian no man's land. With that the obvious 
(the Kafkan moment): the title of the next book, Comment c'est, perhaps suits this one better.

Archetype of a materialist metaphysics.

The novel is completely unrealistic and at the same time unauratic.

Against the term 'absurd'. It presupposes the meaningful as the normal. But that is precisely the illusion[;] the absurd is the normal. - That is already manifest in the controversy over 'story'.

Modern art is the radical heir not only of avant-garde movements but also of Naturalism: a disenchanted world, the illusionless, 'comment c'est'. But

\section{6}

Naturalism is still illusionistic in its form, as though saturated with the toxin of meaning[,] action, etc. When reading the older naturalists, amazement at how little naturalist-how badly stylised they are. B[eckett] gets rid of that, and precisely in so doing distances himself from the photographic-realist façade. Naturalism without aura achieves the aspect which literary criticism then manipulates as the absurd (NB incommensurability of Beckett[,] Ionesco and even Camus). In a second sense, synthesis of radical Expressionism + Naturalism. - The disgusting, the decaying [belong to the] imagery both of Naturalism and of Rimbaud.

Supply a theory of the repellent.

Possibility arising from the doctor's gaze. The gaze on the living from the dissection room. The corpse as the truth about life, what life becomes, and thus the terrible equality before which everything that counts, difference, sinks into irrelevance. Hence the illnesses, mutilations, excretions as 
[7]

the essence of the living. The eccentric is the rule. Hence also the clown. A living being who turns himself into an object, thing, football, dead person.

Is nothingness the same as nothing? Everything in B[eckett] revolves

around that. Absolute discardment, because there is hope only where nothing is retained. The fullness

of nothingness. That is the reason for the insistence on the zero point.

Not abstraction but subtraction 
[7]

the essence of the living. The eccentric is the rule. Hence also the clown. A living being who turns himself into an object, thing, football, dead person.

Is nothingness the same as nothing? Everything in B[eckett] revolves

around that. Absolute discardment, because there is hope only where nothing is retained. The fullness

of nothingness. That is the reason for the insistence on the zero point.

Not abstraction but subtraction 